\title{
A Study on the Origin of Surface Reddening of 65/35 Brass during the Strip Production Process
}

\author{
By K. Asami* and K. Hashimoto*
}

\begin{abstract}
The surfaces of $65 / 35$ brasses with normal and reddish color have been studied by XPS, EPMA and X-ray diffraction. Both brasses are coverd by very thin surface films (2-3 nm thick) and reveal normal zinc contents at a depth of more than $10 \mu \mathrm{m}$. However, the surface region of less than $1 \mu \mathrm{m}$ is fairly dezincified. The dezincification is most serious in the surface within a depth of $10 \mathrm{~nm}$ under the surface film, particularly in the reddened sample. The skin depth of light with a wavelength of $1 \mu \mathrm{m}$ is about $4 \mathrm{~nm}$ for pure metallic copper and the thickness of the surface film is too small to cause the coloration. It was concluded, therefore, that the cause of the reddening is due to the enrichment of copper at the underlying alloy surface by the dezincification.
\end{abstract}

(Received December 27, 1978)

\section{Introduction}

A brass with $35 \% \mathrm{Zn}$ is known to have good rolling and drawing properties and is suitable for deep drawing such as radiator tube, fin, electric wiring and so on. A common name, yellow brass, of the $65 / 35$ brass comes from its yellow color. However, this brass sometimes becomes reddish after the strip production process. The production process involves several cycles of rolling, annealing, and acid pickling. The surface is apt to be reddish when (1) a continuous annealing rather than an annealing in coil is adopted for the intermediate annealing process, (2) the reduction at the final rolling is less than $c a .50 \%$, and (3) the grain size at the final annealing is less than $15 \mu \mathrm{m}$. Surface reddening is almost invariably observed when all of the above conditions are fulfilled. Some reasons can be assumed for the reddening phenomenon. One of the most probable reasons is the formation of a red-colored surface film, for example, $\mathrm{Cu}_{2} \mathrm{O}$. The other is the enrichment of copper by dezincification at the top of the alloy surface under the oxide film.

The purpose of this paper is to clarify the origin of the reddening by use of various techniques for surface analysis.

* The Research Institute for Iron, Steel and Other Metals, Tohoku University, Sendai 980, Japan.

Trans. JIM

\section{Experimental}

Two kinds of samples were cut out from the final strip products, which were $0.25 \mathrm{~mm}$ thick. The chemical composition of both samples was nominally $\mathrm{Cu}-35 \mathrm{wt} \% \mathrm{Zn}-0.03 \mathrm{wt} \% \mathrm{~Pb}-$ $0.05 \mathrm{wt} \% \mathrm{Fe}$. One of the samples was apparently yellow and the other was reddish. The latter sample, (B), was produced through a continuous annealing process of unfastened strip in an electric furnace at $1020 \mathrm{~K}$ for $c a .60 \mathrm{~s}$ as the intermediate annealing, while the former sample, (A), was intermediately annealed in coil at $c a .850 \mathrm{~K}$ for $c a .29 \mathrm{ks}$. Both processes were followed by the same finishing, that is, acid pickling, finishing rolling $(45 \%$ reduction), continuous annealing in unfastened strip at $1020 \mathrm{~K}$ for $20-30 \mathrm{~s}$ and again acid pickling. The acid pickling was made in $10 \% \mathrm{H}_{2} \mathrm{SO}_{4}$ for $4-7 \mathrm{~s}$ at $313-333 \mathrm{~K}$. Tolyltriasol was used as an inhibitor. The specimens were finally degreased in trichloroethylene.

Both samples were examined by means of X-ray photoelectron spectroscopy (XPS) with $\mathrm{Mg} K \alpha$ radiation, electron probe micro-analysis (EPMA or XMA) with an electron accelerating voltage of $25 \mathrm{kV}$, and X-ray diffraction (XD). XPS measurement was carried out with an AEI-KEC-ES 200 electron spectrometer in a vacuum of $c a .4 \times 10^{-7} \mathrm{~Pa}$. The quantitative determination of the compositions of the surface film and the underlying alloy surface

1979 Vol. 20 
and the thickness of the surface film was performed with a similar method to that reported elsewhere ${ }^{(1)}$, though the spectra of $\mathrm{Cu}$ and $\mathrm{Zn}$ used for this purpose were not the photoelectron spectra but the X-ray induced Auger electron spectra. For the quantitative analysis, the peak height intensities of the $\mathrm{Cu} L_{3} M_{4,5} M_{4,5}$ and the $\mathrm{Zn} L_{3} M_{4,5} M_{4,5}$ Auger lines were used. The sensitivity factors of the Auger electrons against the $\mathrm{O} 1 s$ photoelectrons, corresponding to the photo-ionization crosssection ratio, for the $\mathrm{Cu}$ and $\mathrm{Zn} L_{3} M_{4,5} M_{4,5}$ lines were determined from the data on $\mathrm{Cu}_{2} \mathrm{O}$ and $\mathrm{ZnO}$ after Castle and Epler ${ }^{(2)}$ considering the spectrometer factor. Because of the difference in the spectral width of Auger lines between the oxidized and metallic states, the sensitivity factors of the metallic state were taken to be 1.2 times as large as those corresponding to the oxidized state. The spectra of $\mathrm{Cu}_{2} \mathrm{O}$ by Larson ${ }^{(3)}, \mathrm{ZnO}$ by Schön ${ }^{(4)}$ and metallic $\mathrm{Zn}$ by Castle and Epler ${ }^{(2)}$ were used

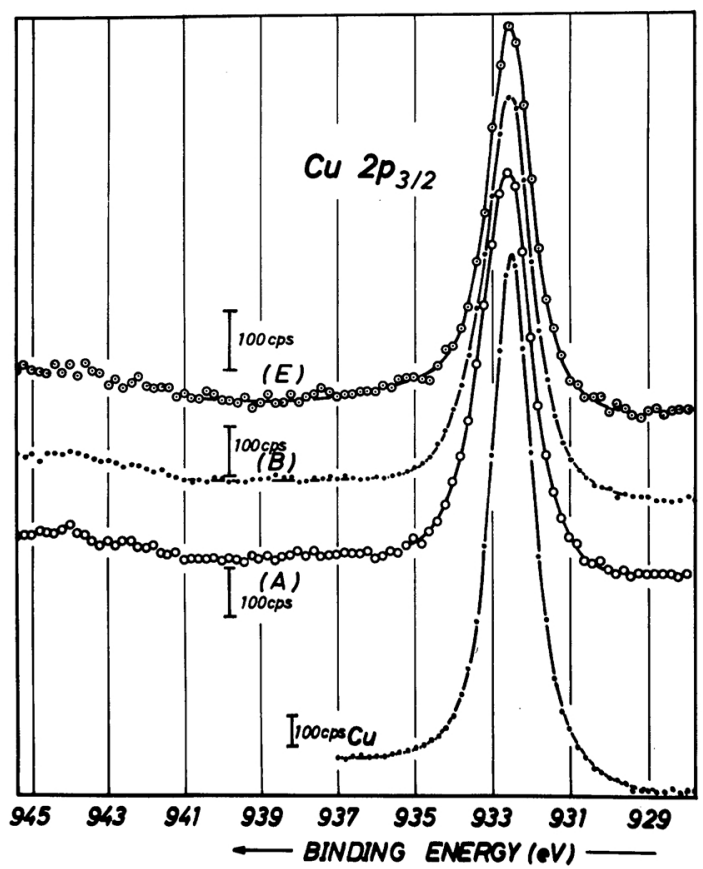

Fig. 1 The $\mathrm{Cu} 2 p_{3 / 2}$ photoelectron spectra. (A); normal $65 / 35$ brass, (B); reddish $65 / 35$ brass, (E); $65 / 35$ brass immediately after being scraped away about $20 \mu \mathrm{m}$ of its surface with $\mathrm{SiC}$ abrasive paper in cyclohexane, and $\mathrm{Cu}$; pure copper heated to $660 \mathrm{~K}$ in a vacuum of the spectrometer. for the standard $L_{3} M_{4,5} M_{4,5}$ Auger spectral shape which was necessary for the separation of the observed spectra into the oxidic and metallic components. The metallic spectrum of $\mathrm{Cu}$ was obtained by heating an emery polished copper sheet to $650 \mathrm{~K}$ in a high vacuum of the spectrometer. The calibration of electron energy detected was made against the $\mathrm{Au} 4 f_{7 / 2}$ and $4 f_{5 / 2}$, the $\mathrm{Cu} 2 \mathrm{p}_{3 / 2}$ and $\mathrm{Cu} L_{3} M_{4,5} M_{4,5}$ peaks from pure gold and copper ${ }^{(5)(6)}$. EPMA was done with a JEOL U-3 type analyser with a take-off angle of $\pi / 6 \mathrm{rad}$. The $K \alpha$ lines of $\mathrm{Cu}$ and $\mathrm{Zn}$ were detected by a $\mathrm{LiF}$ crystal at an acceleration voltage of $25 \mathrm{kV}$. The absorption current was fixed to $2 \times 10^{-8} \mathrm{~A}$. During the EPMA measurement, the samples were mechanically scanned with $20 \mu \mathrm{m} / 60 \mathrm{~s}$ in order to suppress the contamination with carbon deposits as low as possible. The diffractometer was used for the X-ray diffraction measurement with $\mathrm{Cu} K \alpha_{1,2}$ radiation. For comparison, measurements with XPS and EPMA were also made on pure $\mathrm{Cu}$, pure $\mathrm{Zn}$ and $65 / 35$ brass polished in cyclohexane with $\mathrm{SiC}$ abrasive paper.

\section{Results}

\section{XPS measurement}

The photoelectron spectra from samples (A) and (B) showed the existence of $\mathrm{S}, \mathrm{Cl}$ and $\mathrm{C}$ in addition to $\mathrm{Cu}, \mathrm{Zn}$ and $\mathrm{O}$. No detectable enrichment of $\mathrm{Pb}$ and $\mathrm{Fe}$ was observed.

As shown in Fig. 1, the $\mathrm{Cu} 2 p_{3 / 2}$ electron spectrum gives a single peak. The $\mathrm{Zn} 2 p_{3 / 2}$, $\mathrm{Cu} 3 d$ and $\mathrm{Zn} 3 d$ electron spectra were also measured and revealed single peaks. This fact results from very small chemical shifts between spectra of $\mathrm{Zn}^{0}$ in metallic zinc and $\mathrm{Zn}^{2+}$ in zinc oxide ${ }^{(4)}$ and between spectra of $\mathrm{Cu}^{0}$ and $\mathrm{Cu}^{+(2)}$, though the $\mathrm{Cu} 2 p$ electron spectrum of $\mathrm{Cu}^{2+}$ in cupric oxide show a well-defined shift and characteristic large satellites ${ }^{(2)}$.

In contrast to the direct photoelectron spectra, the photo-exicited Auger spectra corresponding to the $L_{3} M_{4,5} M_{4,5}$ transition exhibits distinguishable peaks as shown in Figs. 2 and 3; ones from the surface oxide and the other from the underlying metallic sub- 


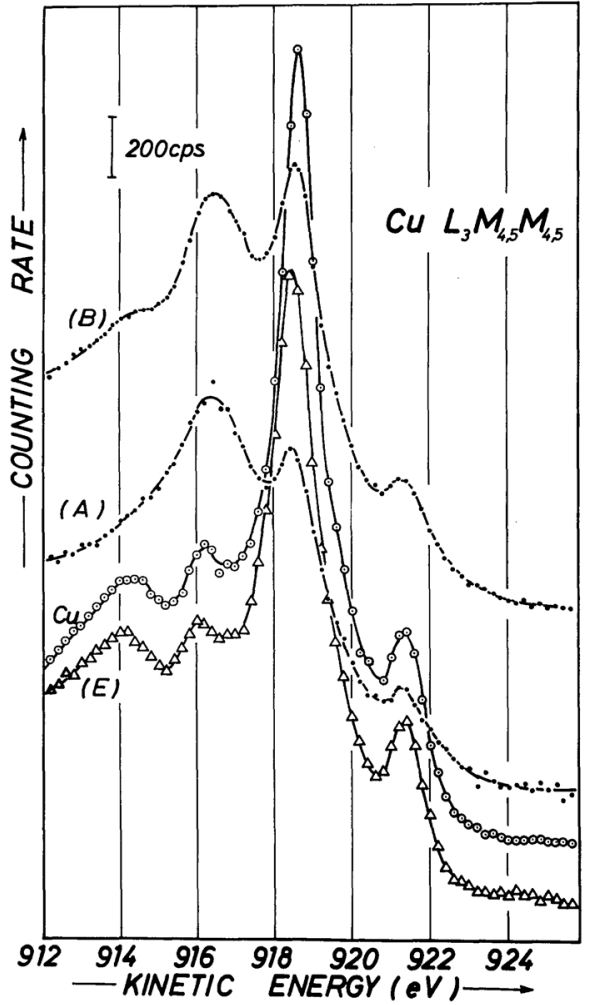

Fig. 2 The $\mathrm{Cu} L_{3} M_{4,5} M_{4,5}$ Auger electron spectra. Curves (A), (B), (E) and Cu correspond to those in Fig. 1, respectively.

strate. The $\mathrm{Zn} L_{3} M_{4,5} M_{4,5}$ Auger spectrum in the oxidized state seems to have two different states. The peak position of $\mathrm{ZnO}$ after $\mathrm{Schön}^{(4)}$ is indicated by an arrow in the Figure. The lower kinetic energy peak coincides with the $\mathrm{ZnO}$ peak. The other would arise from $\mathrm{Zn}(\mathrm{OH})_{2}$ or some other oxide. The $\mathrm{O} 1 s$ spectra of samples consisted of two peaks; one appeared at ca. $530 \mathrm{eV}$ and the other, at $c a .532 \mathrm{eV}$. The former is inferred to the oxygen in metal-Ometal bond and the latter, in metal-OH and metal- $\mathrm{OH}_{2}$ bonds by analogy with the ironchromium-oxygen system ${ }^{(1)(6)}$.

The $\mathrm{S} 2 p$ photoelectron spectra were also composed of two peaks with binding energies of 168.4 and $162.7 \mathrm{eV}$. Bird and Galvin ${ }^{(7)}$ reported the binding energies of the $\mathrm{S} 2 p$ electrons in pure sulfur, iron sulfide and iron (II) sulfate to be $164.3,162.8$ and $168.9 \mathrm{eV}$, respectively, where the binding energy of the $\mathrm{C} 1$ s electrons from contaminant hydrocarbon,

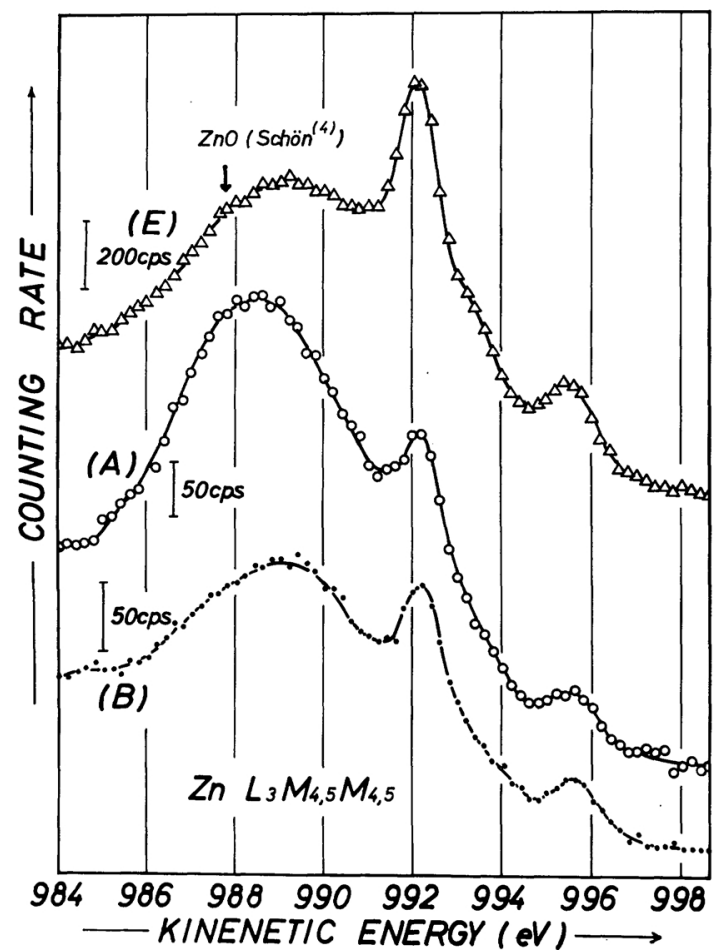

Fig. 3 The $\mathrm{Zn} L_{3} M_{4,5} M_{4,5}$ Auger electron spectra. Curves (A), (B), and (E) correspond to those in Fig. 1, respectively.

$285.0 \mathrm{eV}$, was taken as the energy standard. Larson $^{(3)}$, though the energy calibration method was not described, gave the binding energy of the $\mathrm{S} 2 p$ electrons in $\mathrm{Cu}_{2} \mathrm{~S}$ as $161.7 \mathrm{eV}$. The present authors have observed the $\mathrm{S} 2 p$ spectra on a series of $\mathrm{Fe}-\mathrm{Cr}$ alloys treated in sulfuric acid and on NiS having peaks at 169.3 and $162.6 \mathrm{eV}$, respectively ${ }^{(8)}$. The relationship between the apparent valency of $\mathrm{S}$ and the corresponding binding energy of electrons is given in Fig. 4. It can be said that the peak at $162.7 \mathrm{eV}$ falls exactly on $\mathrm{S}^{2-}$ state; the other peak at $168.4 \mathrm{eV}$ corresponds to the intermediate state between $\mathrm{SO}_{4}^{2-}$ and $\mathrm{SO}_{3}^{2-}$. The spectral intensity ratio of the latter peak to the total S $2 p$ intensity were 0.7 and 0.6 for samples (A) and (B), respectively.

The $\mathrm{Cl} 2 p$ spectrum peak appeared at $198.8 \mathrm{eV}$ which coincided with that from potassium chloride, at $198.6 \mathrm{eV}^{(9)}$, and hence it was assigned to $\mathrm{Cl}^{-}$. The $\mathrm{C} 1 \mathrm{~s}$ spectrum at ca. $285.0 \mathrm{eV}$ was all ascribed to the contaminant 


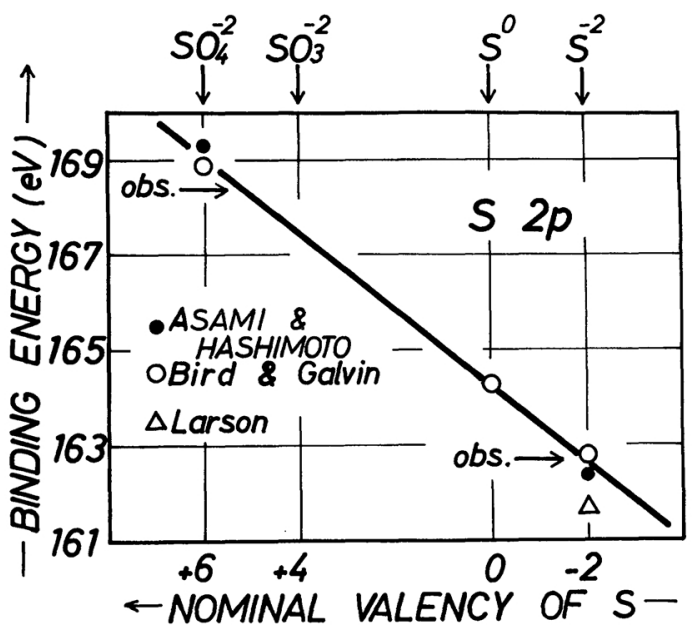

Fig. 4 The relationship between apparent valency of $\mathrm{S}$ and binding energy of the $\mathrm{S} 2 p$ electrons. $o b s . \rightarrow$ in the figure indicates the obsetved peak positions on the $\mathrm{S} 2 p$ spectra of brass samples.

hydrocarbon from diffusion pump oil.

The quantitative determination of the film thickness and composition of the surface oxide film and the composition of the underlying alloy were carried out assuming that $\mathrm{Cu}, \mathrm{Zn}$, $\mathrm{O}, \mathrm{S}, \mathrm{H}$ and $\mathrm{Cl}$ were homogenously distributed through the oxide film which had a uniform thickness and was covered with a uniform contaminant layer. The homogeneous distribution was also assumed for $\mathrm{Cu}$ and $\mathrm{Zn}$ in the underlying alloy within the analysing depth.

The results of XPS are summarized in Table 1. The $\mathrm{Zn}$ content of both samples, (A) and (B), is significantly lowered in the surface film and the underlying alloy compared with their nominal composition. The dezincification is more remarkable in sample (B). One of the most interesting characteristics is the fact that the weight ratio of $\mathrm{Zn}$ to the sum of $\mathrm{Zn}$ and $\mathrm{Cu}$ in surface film is 1.7 times as high as that in the underlying alloy for both samples. It is noticeable that the surface film on emerypolished brass consists mainly of $\mathrm{Zn}^{2+}$ as cationic species but the dezincification in the underlying alloy is not remarkable in comparison with samples (A) and (B).

\section{Results of X-ray diffraction and EPMA}

The lattice spacings obtained from the diffraction angles of (111), (200), (220), (311), (222), (400), (331) and (420) reflections were plotted against $\left(\cos ^{2} \theta / \sin \theta+\cos ^{2} \theta / \theta\right)$. The most probable values of the lattice spacing were determined by the least-squares method and were $0.36926 \mathrm{~nm}$ for sample (A) and $0.36919 \mathrm{~nm}$ for sample (B). The zinc contents for samples (A) and (B) were estimated from the lattice spacing measured, using the relationship between the composition and lattice constant which has been reported by Beck and Smith ${ }^{(10)}$. Compositions of samples (A) and (B) were determined to be $34.7 \mathrm{wt} \%$ and $34.4 \mathrm{wt} \% \mathrm{Zn}$, respectively. No oxide was detected on the diffraction charts.

Corrections for the EPMA measurements were performed with respect to the dead time of the proportional counter, efficiency of backscattering electrons, mass number effect, absorption and fluorescence. The zinc content of samples (A) and (B) were 30.5 and $28.9 \mathrm{wt} \%$, respectively. A sample, with the top layer mechanically polished away by $c a$. $20 \mu \mathrm{m}$, was $34.64 \mathrm{wt} \% \mathrm{Zn}$. This $\mathrm{Zn}$ content probably corresponds to the bulk alloy composition.

Table 1 The results of quantitative XPS analyses of $65 / 35$ brass. Colors of (A) and (B) are normal and reddish, respectively. Sample (E) is scraped away about $20 \mu \mathrm{m}$ of its surface by abrasive SiC paper in cyclohexane immediately before the XPS measurement.

\begin{tabular}{|c|c|c|c|c|c|c|c|c|c|}
\hline \multirow{4}{*}{ Sample } & \multirow{4}{*}{$\underset{\substack{\text { Film } \\
\text { thickness }}}{\text { (nm) }}$} & \multicolumn{8}{|c|}{ Composition } \\
\hline & & \multicolumn{7}{|c|}{ Surface film } & \multirow{3}{*}{$\begin{array}{c}\text { Alloy } \\
\begin{array}{c}\text { [Zn] } \\
(\text { wt. } \%)\end{array}\end{array}$} \\
\hline & & \multicolumn{6}{|c|}{ (wt. \%) } & \multirow{2}{*}{$\frac{[\mathrm{Zn}] \times 100}{[\mathrm{Zn}+\mathrm{Cu}]}$} & \\
\hline & & $\mathrm{Cu}$ & $\mathrm{Zn}$ & 0 & $\mathrm{H}$ & $\mathbf{S}$ & $\mathrm{Cl}$ & & \\
\hline (A) & 2.7 & 55.4 & 17.4 & 21.2 & 0.8 & 2.7 & 2.6 & 23.9 & 14.1 \\
\hline (B) & 2.0 & 66.0 & 9.6 & 17.9 & 0.6 & 1.3 & 4.6 & 12.8 & 7.4 \\
\hline (E) & 0.7 & 6.7 & 61.8 & 30.5 & 1.0 & - & - & 90.3 & 24.7 \\
\hline
\end{tabular}




\section{Discussion}

The XPS results show that copper is contained as cuprous ion in the surface film on both samples (A) and (B). Chlorine and sulfur are contaminant elements. The former is possibly attached through degreasing by trichloroethylene. The latter may arise from sulfuric acid for acid pickling and the contaminated atmosphere containing $\mathrm{SO}_{2}$ around the factory.

According to XPS analysis, for both the reddish and normal-colored samples, the weight ratio of $\mathrm{Zn}$ to the total cation, $(\mathrm{Zn}+\mathrm{Cu})$, in the surface film is $c a .1 .7$ times the weight fraction of $\mathrm{Zn}$ in the underlying alloy regardless of the degree of dezincification. This fact suggests that the cationic fraction of surface film is mainly determined by the surface composition of the underlying alloy prepared by acid pickling. On the other hand, the surface oxide is $3 \mathrm{~nm}$ thick at most as shown in Table 1 . It is, therefore, natural that the XD method could not detect the existence of the surface oxide even if it is crystalline. Usually, this kind of thin surface film formed on brass is protective to further atmospheric corrosion and prevents film thickening, due mainly to its electrically insulating property ${ }^{(11)}$. Such a thin insulator should be transparent to the most of electromagnetic waves including the visible light. Accordingly, the surface film which exists on both samples cannot be a cause of the difference in apparent color.

The dezincification was clearly observed in XPS results. It is, however, not significant in EPMA results and even not detected by XD. In XPS, the escape depth of photoelectrons is about a few $\mathrm{nm}$ when photoelectrons are excited by the $\mathrm{Al}$ or $\mathrm{Mg} K \alpha$ radiation. Therefore, the analysing depth of the XPS is not more than a few tens of $\mathrm{nm}$. On the other hand, the linear absorption coefficient of the $\mathrm{Cu} K \alpha$ radiation in brass is about $45 \mathrm{~mm}^{-1}$. In EPMA, the analysing depth is usually considered to be of the order of $1 \mu \mathrm{m}$. The difference in composition among different analysing method with different analysing depth tells the existence of a large composition gradient in the alloy surface of the brass product.

The analysing depth, $L$, is defined as follows: when the fraction $G_{L}$ of the total signal intensity is detectable from the thickness range $L$ of a homogenous substance of semi-infinite thickness, the thickness $L$ is the analysing depth. In this report, $G_{L}$ is taken as 0.78 for convenience, that is,

$$
G_{L}=\int_{0}^{L} d I / \int_{0}^{\infty} d I=0.78,
$$

where $I$ is the signal intensity. For XPS, the analysing depth is

$$
L(\mathrm{XPS})=-\lambda \sin \theta \cdot \ln \left(1-G_{L}\right),
$$

where $\lambda$ is the mean value of escape depth of the $\mathrm{Cu}$ and $\mathrm{Zn} L_{3} M_{4,5} M_{4,5}$ Auger electrons, and $\theta$ is the take-off angle of photoelectrons. In the case of the diffractometer, $L(\mathrm{XD})$ is expressed as follows using $\mu$ (the linear absorption coefficient of diffracting $\mathrm{X}$-ray in brass), $\lambda_{X}$ (the wavelength of the X-ray) and $d_{h k l}$ [the lattice spacing with $(h k l)]$ :

$$
L(\mathrm{XD})=-\left(\lambda_{X} / 4 d_{k k l} \mu\right) \cdot \ln \left(1-G_{L}\right) .
$$

The analysing depth for EPMA cannot be expressed in a simple formula since it contains the ionization distribution function. Accordingly, $L($ EPMA) was obtained graphically under the condition of eq. (4):

$$
\begin{aligned}
& \int_{0}^{\rho L(\text { EPMA })} \phi(\rho l) \mathrm{e}^{-\chi \rho l} d(\rho l) \\
& / \int_{0}^{\infty} \phi(\rho l) \mathrm{e}^{-\chi \rho l} d(\rho l)=0.78,
\end{aligned}
$$

where $\phi$ is the ionization distribution function, $\rho$ is the density of the sample, $l$ is the distance measured from the top of the sample surface, $\chi=(\mu / \rho) / \sin \theta_{X}, \quad \mu$ is the linear absorption coefficient of the analysing $\mathrm{X}$-rays, and $\theta_{X}$ is the take-off angle of $\mathrm{X}$-ray. The analysing depths thus estimated are $1.6 \times 10^{-3} \mu \mathrm{m}$ for XPS, $15 \mu \mathrm{m}$ for XD and $0.57 \mu \mathrm{m}$ for EPMA in this report.

The composition is plotted versus the analysing depth in Fig. 5. Figure 5, corresponding to an in-depth profile, shows explicitly the distribution of the dezincified region.

Metals and alloys are non-transparent to electromagnetic waves because of the existence 
of high density of conduction electrons. It can, therefore, be said that the composition of the top-most thin layer about several nm thick controls the color of the metallic substance. For example, let's estimate an attenuation depth of light with wave length of $1 \mu \mathrm{m}$, which belongs rather to infrared ray, in pure copper at $300 \mathrm{~K}$. An amplitude $E$, at depth $z$ in metal, of the electromagnetic wave incident to metal is expressed as follows ${ }^{(12)}$ :

$$
E \propto \exp \left(-z / \delta_{0}\right) \cdot \exp \left(i z / \delta_{0}\right),
$$

where $\delta_{0}=c / \sqrt{2 \pi \sigma \omega}, c$ : the light velocity, $\sigma$ : the electrical conductivity, and $\omega$ : the angular frequency of incident wave. Taking $\sigma=5 \times$ $10^{17} \mathrm{~s}^{-1}$ (the d.c. conductivity of copper at $300 \mathrm{~K}), \delta_{0}=4 \mathrm{~nm}$ for a light with a wavelength of $1 \mu \mathrm{m}$. This means, from eq. (5), that the amplitude of the incident wave attenuates to $\mathrm{e}^{-1}$ at depth $\delta_{0}$ compared with that out of metal. When the anomalous skin effect is taken into account, the attenuation depth corresponding to $\delta_{0}$ is $c a .8 \mathrm{~nm}$. $\delta_{0}$ for visible light should be smaller because it is inversely proportional to $\sqrt{ } \omega$. This fact suggests that brass may change its color even the dezincification is not serious except within the depth less than only $10 \mathrm{~nm}$. The results shown in Fig. 5 actually shows that the dezincification of sample (B) is severer than that of sample $(\mathrm{A})$ and the zinc content in (B) is nearly half of that in (A) in the surface region less deeper than $\delta_{0}$. It is conceivable that, when the surface of reddish brass

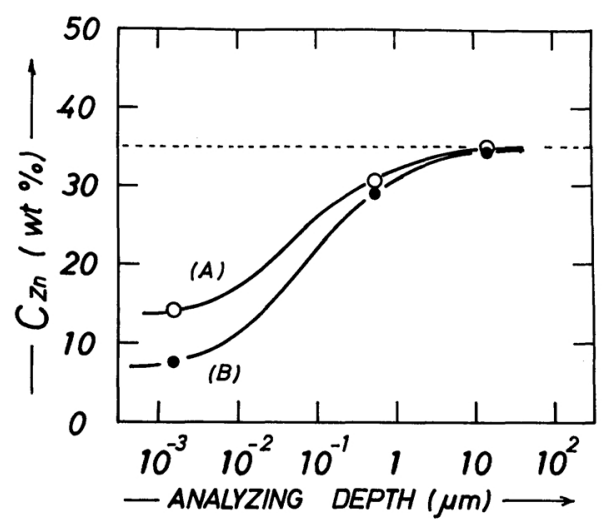

Fig. 5 The relationship between zinc content and analysing depth. (A); normally yellow sample, and (B); reddened sample. similar to (B) is scraped away ca. $1 \mu \mathrm{m}$, it turns to normal yellow brass. The conditions which leads brass to be reddish can also be explained by the observed fact: the continuous annealing process in open atmosphere for relatively short time would give less chance, compared with the annealing process in coil for a long time, for zinc to diffuse from bulk alloy to the surface compensating the dezincified region; the rolling process would reduce the thickness of the dezincified region and particularly the softened dezincified region would preferably reduced. The lower the reduction by rolling, the more remarkable becomes the tendency to reddening; and the small grain size would facilitate the diffusion of zinc to the surface through the grain boundaries.

\section{Conclusion}

The $65 / 35$ brass strips produced by a combination of rolling, annealing and acid pickling with inhibitor are covered with $c a .2-3 \mathrm{~nm}$ thick surface film, which contains $\mathrm{Cu}^{+}$and $\mathrm{Zn}^{2+}$ as cations. The ratio of $\left[\mathrm{Cu}^{+}\right] /\left[\mathrm{Zn}^{2+}\right]$ in the surface film is dependent on the composition of the alloy surface just beneath the surface film since it is formed by air-exposure of the bare alloy surface prepared by acid pickling.

The thickness of the surface film is so small that the existence of the surface film itself cannot be the origin of the reddening of brass.

The dezincification is observed on both normal and reddened brasses in surface region less than $1 \mu \mathrm{m}$ deep, irrespective of their color. The zinc content in reddish brass is less than $10 \mathrm{wt} \%$ and is about a half of that in normal brass in the depth range of less than $10^{-2} \mu \mathrm{m}$, which is the same order of magnitude as the maximum depth for the attenuation of visible light. Thus, the severe dezincification, to less than $10 \mathrm{wt} \% \mathrm{Zn}$, of the surface region of less than $1 \mu \mathrm{m}$ deep, is the main cause of brass reddening during the strip production process.

\section{Acknowledgement}

We would like to thank Messrs. T. Umeda and T. Yamaguchi for sample preparation and helpful discussions. 


\section{REFERENCES}

(1) K. Asami, K. Hashimoto and S. Shimodaira: Corros. Sci., 17 (1977), 713.

(2) J. E. Castle and D. Epler: Proc. R. Soc. Lond., A 339 (1974), 49.

(3) P. E. Larson: J. Electron Spectrosc., 5 (1974), 213.

(4) G. Schön: J. Electron Spectrosc., 2 (1973), 75.

(5) K. Asami: J. Electron Spectrosc., 9 (1976), 469.

(6) K. Asami and K. Hashimoto: Corros. Sci., 17 (1977), 559.
(7) R. J. Bird and G. D. Galvin: Wear, 39 (1976), 143.

(8) K. Asami and K. Hashimoto: unpublished data.

(9) M. Hara, K. Asami, K. Hashimoto and T. Masumoto, to be published.

(10) L. H. Beck and C. S. Smith: J. Metals 5 (1952), 1079.

(11) N. Cabrera and N. F. Mott: Repts. Progr. in Phys., 12 (1946), 163.

(12) C. Kittel: "Introduction to Solid State Physics", 3rd ed., John Wiley \& Sons, Inc., New York, (1966), p. 230. 